John Carroll University

Carroll Collected

2018 Faculty Bibliography

Faculty Bibliographies Community Homepage

2018

\title{
Race and the extra-legal punishment of professional athletes
}

Samuel V. Bruton

University of Southern Mississippi

Donald F. Sacco

University of Southern Mississippi

Earl W. Spurgin

John Carroll University, espurgin@jcu.edu

Kori N. Armstrong

University of Southern Mississippi

Follow this and additional works at: https://collected.jcu.edu/fac_bib_2018

Part of the Applied Ethics Commons, and the Sports Studies Commons

\section{Recommended Citation}

Bruton, Samuel V.; Sacco, Donald F.; Spurgin, Earl W.; and Armstrong, Kori N., "Race and the extra-legal punishment of professional athletes" (2018). 2018 Faculty Bibliography. 75.

https://collected.jcu.edu/fac_bib_2018/75 


\title{
Race and the extra-legal punishment of professional athletes
}

\begin{abstract}
In recent years, major American sports teams and leagues have responded increasingly to players' off-field, off-court wrongdoing by imposing extra-legal punishments (ELPs) on offending athletes. This paper focuses on an unexplored ethical concern raised by ELPs: teams' and leagues' economic incentive for racial bias in the imposed sanctions. In an experimental study, Black and White participants read a series of vignettes about fictional professional athletes who received ELPs for various off-field transgressions. Black participants evaluating punishments imposed on Black athletes found the ELPs inappropriate and overly punitive relative to punishments imposed on White or racially neutral athletes. Conversely, Whites assessing ELPs imposed on Whites found them too harsh. These findings suggest that the race of both perceiver and target influence lay persons' judgements about ELPs, which raises questions about the ability and willingness of teams and leagues to impose such punishments fairly and consistently, given their business interests.
\end{abstract}

\section{Introduction}

In recent years, major American sports teams and leagues have responded increasingly to players' off-field, off-court wrongdoing by imposing extra-legal punishments (ELPs) on offending athletes. A recent illustration of this trend is the National Football League's (NFL) suspension of Dallas Cowboys running back Ezekiel Elliott (Archer 2017). Elliott was suspended for six games following allegations of domestic violence by a former girlfriend. Three years ago, the league suspended Baltimore Ravens running back Ray Rice indefinitely after video surfaced of Rice hitting and dragging his then-fiancée Janay Palmer from a hotel elevator (Bien 2014). ${ }^{1}$ Other recent examples include Jahlil Okafor, centre for the National Basketball Association's (NBA) Philadelphia 76ers, and shortstop Jose Reyes of Major League Baseball's (MLB) Colorado Rockies. Okafor was displined for fighting a heckler following a 
game (Pompey 2015); Reyes's punishment followed his arrest for a domestic dispute (Gibbs 2016). Perhaps the best-known ELP involved NFL quarterback Michael Vick, who was suspended after serving time in federal prison for his role in a dog-fighting ring (ESPN 2010).

For present purposes, ELPs refer to certain kinds of disciplinary measures placed on professional athletes by their teams or leagues. They are extra-legal in two respects. First, they are independent of punishments imposed by the criminal justice system or through civil proceedings. Second, they exclude penalties levied for violations of the rules of competition, including both rule-breaking within the scope of play and for the use of performance-enhancing drugs. They also are distinct from extra-legal player-versus-player retaliations for violations of 'the code' (Bernstein 2006), as when a pitcher in baseball deliberately hits a batter because a teammate of the batter is thought to have 'shown him up'. ELPs, by contrast, are a response to misconduct in players' non-professional or personal lives. This paper focuses on an ethical concern regarding ELPs heretofore ignored in the academic literature: the incentive teams and leagues have to be racially baised in the imposition of punishment for off-field, off-court wrongdoing.

The a priori case for such bias is credible. Sports franchises and leagues have a business interest in pleasing their fans, and fan reaction to athletes' misbehaviour is susceptible to typical preferences, biases, and stereotypes, including those involving race. What best mollifies outraged sports consumers may not best accord with raceneutral justice. This point has special force given racial disparities between the athletes and spectators of the major US professional sports, and the NFL and NBA in particular. These are the two most popular professional leagues (in terms of television ratings), and they are now predominantly Black. Although the audience for these sports remains mostly White, and the United States is approximately $77 \%$ White and $13 \%$ Black overall (US Census Bureau 2015), ${ }^{2}$ almost $69 \%$ of NFL players are Black as are $74 \%$ of NBA players (Lapchick and Guiao 2015). This disproportionality suggests that to optimize the marketability of their products, the leagues need to be sensitive to how athletes' off-field behaviour affects brand image. The NFL in particular has long used its player conduct policy to enhance its popularity (Ambrose 2008).

A good example of race-conscious damage control by a professional sports league is the well-documented attempt of the NBA to downplay the league's perceived 'blackness' after the notorious 'Malice at the Palace' game in 2004 (Leonard 2012). News reports of the incident showed Ron Artest and other Black ${ }^{3}$ players charging into the stands to fight mostly White spectators. More recently, the NFL has de facto banished Colin Kaepernick from the league after he refused to stand for the traditional pre-game playing of the Star Spangled Banner. Kaepernick acted in protest of minimal punishments given to police officers who shoot Black citizens. After other NFL players began emulating the Black quarterback's silent demonstration, polls showed 59\% of Whites thought players were wrong to kneel during the national anthem, while $82 \%$ of Blacks thought kneeling was the right thing to do (Agiesta 2017). Following his protest, no team has shown the slightest interest in re-signing Kaepernick, a talented, young free agent (Hiltzik 2017). Although these instances do not involve ELPs, they show that owners and leagues are keenly aware of public 
reaction to Black athletes who behave in ways that are viewed as transgressive and threatening.

In addition to their business interests, owners often harbor racial biases of their own. This was recently made clear by Bob McNair, owner of the NFL's Houston Texans, and Donald Sterling, former owner of the NBA's Los Angeles Clippers. In an NFL, owners meeting called to address the wave of Kaepernick-inspired protests by players, McNair commented that '[the owners] can't have the inmates running the prison' (Stites 2017). Sterling was secretly recorded making vile, racist remarks that were later made public (Branch 2014). Like McNair and Sterling, the overwhelming majority of team owners are older, White males. As of $2013,98 \%$ of majority owners of NBA Teams, $97 \%$ of majority owners of NFL teams, and $98 \%$ of majority owners of MLB teams were White (Chalabi 2014).

After reviewing some of the relevant literature, this paper presents the results of an experimental study showing racial ingroup-outgroup bias in lay peoples' evalutations of ELPs. The data were collected by asking participants to assess specific ELPs in various scenarios. Though fictionalized, the incidents and hypothesized punishments were modeled on actual cases. Exclusively, the scenarios involved players from the three major American professional sports of football, baseball and basketball, in part, because of high fan interest in those sports and those leagues' racial diversity. Piquero et al. (2011) showed that race played a prominent role in fan reaction to Michael Vick's punishment and subsequent reinstatement; we hypothesized that this disparity would generalize across other sports and to other kinds of wrongdoing. By design, our study does not show that actual racial bias has occurred in the ELPs imposed by leagues and teams. Direct evidence for such bias would be difficult to establish, for reasons described below. Nonetheless, if fans tend to view athletes' wrongdoing through a racial lens, given the incentive professional sports teams and leagues have to be sensitive to the public image of their athletes, racial bias in lay assessments of ELPs raises important questions about the ethics and potential unfairness of such sanctions.

\section{The ethics of ELP}

Legally speaking, ELPs are unproblematic. Teams and leagues have broad, legal prerogatives to punish players for misdeeds committed outside the scope of play. This permissibility derives from multiple overlapping powers. Under league constitutions, collective bargaining agreements, and bylaws, commissioners have the right to discipline players in the 'best interest' of their respective sports (Kim and Parlow 2009; Withers 2010). Collective bargaining agreements detail procedures by which fines, suspensions, and other penalties are to be apportioned and by which grievances and appeals are to be adjudicated (Sirotkin 2009; Parlow 2010). Owners gain additional rights through morals clauses included in players' individual contracts (Trebon 2007; Kim and Parlow 2009). Recently, leagues have used this latitude to adopt more stringent policies towards player misconduct, especially for allegations of domestic violence. NFL owners recently updated the league's Personal Conduct Policy, thereby strengthening the 2007 version (NFL 2014). These changes were made after numerous 
incidents involving players' criminal behaviour came to light (Levin 2014). Also in 2014, the NBA imposed its first suspension ever for domestic violence (Davidson 2014). For its part, MLB recently enacted its first policy governing allegations of domestic violence, sexual assault and child abuse (Oz 2015).

However, ELPs raise several ethical concerns. One involves the legitimacy of workrelated punishment for non-work behaviour. Ordinarily, it is thought inappropriate for an employer to fine or suspend an employee from the workplace for alleged nonworkplace conduct. Such behaviour is typically considered 'none of the employer's business' except insofar as on-the-job performance is affected. In a similar vein, one commentator has argued that unless athletes put themselves forward as role models, privacy considerations limit their obligations to the public or their employers regarding their personal behaviour (Spurgin 2012).

Employer-imposed ELPs also raise questions about due process. Punishments assessed by the NFL, NBA and MLB to date show that athletes often are punished not merely when they have been formally convicted in a court of law, but for mere allegations raised against them. Ezekiel Elliott was suspended despite not being charged with a crime by the Ohio authorities who investigated the case, and neither the NFL arbitrator nor the league's investigator in the matter was involved in the meeting with commissioner Roger Goodell that led to Elliott's suspension (Archer 2017). While leagues have appeals processes, these procedures remain dominated by the same league officials responsible for determining the original punishments.

The leagues' track records raise questions as well about the kinds of offenses they deem worthy of sanction. In some cases, leagues have responded strongly to undesirable off-field conduct. The NFL suspended Terrelle Pryor five games for accepting cash for memorabilia while in college, something he did before joining the league (Van Bibber 2014), and former MLB Commissioner Bud Selig suspended Atlanta Braves' pitcher John Rocker from spring training and a month of the season for racist and homophobic comments (Chass 2000). The NFL and NBA have been harsh in their treatment of recreational drug usage, despite increasingly relaxed social attitudes about it. However, the NFL did not suspend Ray Lewis, a Baltimore Ravens linebacker who pled guilty to obstruction of justice charges resulting from his involvement in a double murder. ${ }^{4}$ Commissioner Goodell originally imposed only a twogame suspension on Ray Rice; he elevated it to an indefinite suspension only after questions arose about the extent of the NFL's knowledge of the incident (Bien 2014). Giant placekicker Josh Brown, after initially serving a one-game suspension, was suspended an additional six games by the NFL after unspecified 'new info' came to light (Grautski 2017).

\section{Previous research and data}

The ethical issue explored in this paper is the leagues' incentive for racial bias in the administration of ELPs. Racial categories significantly shape how people think about the ethics of others' behaviour and the appropriateness of punishments for that behaviour. As Larrick notes, 'human beings appear to be hard-wired to think in terms of "us versus them" and to value loyalty to the ingroup' (Larrick 2016, 456, citing 
Brewer 1999; Hogg and Terry 2000; Haidt 2007). Perceptions of an 'us' versus a 'them' seem particularly important to assessments of morality and wrongdoing (Uhlmann et al. 2009; see also Schiller, Baumgartner, and Knoch 2014), and race is a particularly efficient marker of ingroup-outgroup membership (Dickter and Bartholow 2007).

As has been demonstrated in many contexts, racial categories produce various conscious and unconscious stereotypes and biases. Some of the best-known evidence comes from the implicit association test (IAT) (Banaji and Greenwald 2016; Schiller et al. 2016). Among other findings, these tests show mock jurors implicitly link 'Black' with 'Guilty' (Levinson, Cai, and Young 2010). ${ }^{5}$ The majority of White Americans hold the stereotype that Blacks are more violent, not as hard-working, and are less intelligent than themselves (Bodenhausen 1988; Lapchick 2000), and such background beliefs are especially salient in judgements of criminal behaviour.

Given demographics, prevailing stereotypes, and existing imbalances of social power, most research has documented biases that adversely affect Blacks. A multitude of studies show that Black men are found guilty more often than White men (Pfeifer 1990; Pfeifer and Ogloff 1991; Sommers 2007; Mays et al. 2013), and similar evidence shows White jurors are significantly more likely to convict Black defendants than they are White defendants (Sommers and Ellsworth 2001; Levinson, Cai, and Young 2010). Blacks receive longer prison sentences than either Whites or Hispanics, even after controlling for the severity of the offense, prior criminal histories, and sentencing tendencies in the district (Mustard 2001). Even amongst youths who have never been sent to juvenile prison, Blacks are more than six times likelier to be sentenced to prison for identical crimes than are Whites (Poe-Yamagata and Jones 2000, as cited by Alexander 2011, 118). Yet Cohn et al. (2009) found that both Black and White jurors are more likely to find defendants of the opposite race guilty, and Butler (1995) argues that jurors are less likely to convict defendants of their own race even if they believe that they are guilty.

The so-called 'outrage heuristic' also is relevant in punishment contexts (Kahneman and Frederick 2002; Sunstein 2003). Ethically, we think that punishment should 'fit the crime'. Considerations of fairness also require punishing misconduct with consistency, taking relevant aggravating and mitigating factors into account. Such judgements, however, are cognitively demanding. How many games should one be suspended, or how big a fine should one pay, for beating a wife or girlfriend? Thinking through the relevant factors and making appropriate comparisons to relevantly similar scenarios is not an easy task. Rather than go to the trouble, it seems that people often assess punishments by comparing them to their affective responses (Kahneman and Frederick 2002). We typically gauge the appropriateness of punishments in terms of whether what is imposed is proportional to our feelings about the bad behaviour. Cognitively difficult tasks also make it more likely that evaluators will rely on stereotypes (Bodenhausen 1990).

Also relevant is the almost tribal connection between sports fandom and self-identity. A revealing study demonstrated on a neural level the significance of intergroup competition to self-identity (Cikara, Botvinick, and Fiske 2011). When fans saw images of their own team doing well, fMRI (functional magnetic resonance imaging) 
scans showed increased activity in the ventral striatum, the brain's pleasure centre. These reactions were confirmed by fans' self-reports. The section of the brain where pain is experienced - the anterior cingulate cortex - was activated when the fans were exposed to images of their teams doing poorly. When viewing rival teams, fans experienced the opposite emotions. Viewing the rival teams' misfortunes produced a response of pleasure; the rival's success produced pain. Intergroup conflict and status, of course, has long been thought an important aspect of our social identities and selfesteem (Tajfel and Turner 1986).

\section{Method}

One way to study racial bias of ELPs in professional sports would be to examine punishments teams and leagues have doled out, instance by instance. Such an approach, however, would face two significant obstacles. First, as mentioned earlier, league policies in this area are something of a 'moving target'. At present, for example, there seems much less tolerance for domestic violence than there was a decade ago. This evolution of standards makes it difficult to find significant numbers of similar offenses punished under the same rules. Sample size problems are exacerbated by a second obstacle: there are almost always relevant differences between cases, although pertinent details often remain 'behind closed doors' and are unknown to all but a select few. Consequently, this study employed an experimental methodology in which research participants evaluated twelve scenarios involving athletes who had committed criminal offenses.

\section{Participants}

268 participants (56 men, 212 women; mean age $=21.28$ years, SD $=5.26$ years) voluntarily completed study procedures. The sample consisted of 157 White participants, 94 Black participants, 9 Asian-American participants, and 8 individuals who reported being of at least two races or ethnicities. Given the nature of the research, only White and Black participants were included in the primary analysis (51 men, 200 women).

\section{Materials}

\section{Athlete Criminal Behaviour Scenarios}

Participants completed a questionnaire consisting of 12 scenarios. Each scenario was approximately a paragraph in length and described a criminal offense committed by an athlete from the NFL, NBA, or MLB. The scenarios also described an ELP the player's team or league imposed. While fictionalized, the scenarios were modeled on actual offenses committed by athletes from these leagues over the last few years. The offenses ranged in severity and levels of violence, from unruliness and hotel-property destruction to domestic violence, animal cruelty, and drug possession. Due to the sport and player names (where given), all the athletes were identifiably male.

Three versions of these scenarios were created. In the control condition, none of the characters were named; in the Black name condition, the main athlete in all 
scenarios had a stereotypically Black name; in the White name condition, the main athlete in all scenarios had a stereotypically White name. ${ }^{6}$ Participants were randomly assigned to one of the three conditions on a between-participant basis.

Scenarios were presented to participants in a randomized order. At the conclusion of each scenario, participants were asked to respond to two questions: (1) Given the nature of the off-field behaviour described in the scenario, is it appropriate for the league to impose additional penalties at all, above and beyond those imposed through the legal process? ( $1=$ Not at all appropriate, $4=$ Neutral, $7=$ Perfectly appropriate), and (2) Is the league's punishment of him too harsh or too lenient? ( 1 = Too lenient, $4=$ About right, 7 = Too harsh). These questions were distinguished because whether or not punishment is appropriate at all is distinct from whether a particular punishment is appropriately severe. Across all scenarios, the reliability of these two questions was acceptable ( $\alpha=.84$ and .77 , respectively); consequently, each participant's responses were averaged across all scenarios. Higher scores reflect greater perceptions of increased appropriateness and perceptions of increased harshness of punishment, respectively.

\section{Demographics}

Participants also completed a demographics form in which they reported age, race, and gender.

\section{Procedure}

Data were collected online at a midsized, southeastern US university. Participants were introductory psychology students who were offered class extra-credit. After providing informed consent, participants completed the questionnaire and demographics form, and then were redirected to an online debriefing.

\section{Results}

\section{Appropriateness of league's additional penalties}

To determine possible relationships between participants' and target athletes' race and perceptions of the appropriateness of ELPs, participants' responses were analysed using a 2 participant race (White, Black) $\times 3$ condition (White name, Black name, No name) univariate ANOVA. The main effect of condition was not significant, $F(2,245)=.530, p=.589, \eta_{p}^{2}=.020$. There was a significant main effect of participant race, $F(1,245)=38.03, p<.001, \eta_{p}^{2}=.134$; Black participants indicated that the additional penalties were less appropriate $(M=4.64, S D=.92)$ compared to White participants $(M=5.37, S D=.93)$. Importantly, there was an interaction between participant race and condition, $F(2,245)=6.33, p=.002, \eta_{p}^{2}=.049$.

To better understand this interaction, we conducted 2, one-way ANOVAs with participants' additional punishment appropriateness scores as the dependent variable and condition as the independent variable. For White participants, the effect of condition was nonsignificant, $F(2,154)=2.29, p=.104, \eta_{p}^{2}=.029 .^{7}$ Nonetheless, exploratory post hoc LSD tests revealed that White participants in the White name condition 
$(M=5.14, S D=.93)$ thought that the additional punishment was marginally less appropriate than White participants in the No name $(M=5.50, S D=.92), p=.051$, $d=.39$, and Black name conditions $(M=5.45, S D=.90), p=.087, d=.34$; White participants in the No name and Black name conditions did not differ with respect to ratings of punishment appropriateness $(p=.787, d=.05)$. For Black participants, the effect of condition was significant, $F(2,91)=4.46, p=.014, \eta_{p}^{2}=.089$. Post hoc LSD tests revealed that Black participants in the White name condition $(M=4.97, S D=$ .88) thought that the additional punishment was marginally more appropriate than Black participants in the No name $(M=4.49, S D=.99), p=.053, d=.51$, and Black name condition $(M=4.38, S D=.84), p=.005, d=.69$; Black participants in the No name and Black name conditions did not differ $(p=.658, d=.12)$.

Because the midpoint of our scale was neutral, any values significantly greater than 4 can be considered support for the additional punishment. As such, we conducted one-sample $t$-tests for Black and White participants' scores regarding the appropriateness of additional punishment for the Black, White, and No name conditions. In all cases, the mean scores were significantly above the midpoint, indicating that Black and White participants believed the additional punishment to be appropriate (all ps $<.04$ ). Thus, the results based on participant and athlete race are consistent with greater outgroup derogation than ingroup favouritism, given their relationship to the midpoint.

\section{Perceptions of harshness of league's additional penalties}

To determine if participant race and target race influence perceptions of the perceived harshness of the leagues' additional penalties, we subjected participants' perceived harshness scores to a 2 participant race (White, Black) $\times 3$ condition (White name, Black name, No name) univariate ANOVA. The main effect of condition was marginally significant, $F(2,245)=2.48, p=.086, \eta_{p}^{2}=.020$; post hoc tests revealed that compared to the No name condition participants $(M=3.33, S D=.78)$, participants in the Black name $(M=3.59, S D=.71), p=.028, d=.35$, and White name conditions $(M=3.62, S D=.76), p=.013, d=.38$, perceived the punishment as more harsh; White name and Black name participants did not differ in their harshness ratings ( $p$ $=.757, d=.04)$. There was also a significant main effect of participant race, $F(1,245)$ $=7.04, p=.009, \eta_{p}^{2}=.028$; Black participants indicated that the additional penalties were harsher $(M=3.70, S D=.76)$ compared to White participants $(M=3.42, S D=$ .73). Importantly, there was an interaction between participant race and condition, $F(2,245)=4.68, p=.010, \eta_{p}^{2}=.037$.

To better understand this interaction, we conducted two, one-way ANOVAs with participants' perceived harshness scores as the dependent variable and condition as the independent variable. For White participants, the effect of condition was signifi-

cant, $F(2,154)=4.64, p=.011, \eta_{p}^{2}=.057$. Post hoc LSD tests revealed that White participants in the White name condition $(M=3.66, S D=.62)$ thought that the additional punishment was significantly harsher than White participants in the No name $(M=3.25, S D=.81), p=.004, d=.57$, and Black name conditions $(M=3.36, S D=$ $.70), p=.029, d=.45$; White participants in the No name and Black name conditions 
did not differ $(p=.443, d=.15)$. For Black participants, the effect of condition was marginally significant, $F(2,91)=2.95, p=.057, \eta_{p}^{2}=.061$. Post hoc LSD tests revealed that Black participants in the Black name condition $(M=3.94, S D=.55)$ thought that the additional punishment was significantly harsher than Black participants in the No name $(M=3.53, S D=.67), p=.050, d=.67$, and White name condition $(M=3.57, S D=.92), p=.037, d=.49$; Black participants in the No name and White name conditions did not differ $(p=.826, d=.05)$.

Because the midpoint of our scale was 'just right', any values significantly lower than 4 indicate participants believe the punishment was too lenient. As such, we conducted one-sample $t$-tests for Black and White participants' scores regarding perceptions of harshness of additional punishment for the Black, White, and No name conditions. In all but one case, the mean scores were significantly below the midpoint, indicating that Black and White participants believed the additional punishment to be too lenient (all ps <.01). Thus, the results based on participant and athlete race suggest a possibly greater impact of outgroup derogation rather than ingroup favouritism, although both processes are likely at work in the findings. The lone exception was Black participants' harshness evaluation of the Black athlete condition, in which harshness ratings were not significantly different from the midpoint, $t(35)=.67, p=.509$.

Despite significantly more women than men in our sample, the data revealed no violations of homogeneity of variance, indicating that response variability was equivalent between men and women. Further, when participant gender was included in the statistical model, participant gender did not qualify the results $(F s<2$; $p>.14$ ). Thus, men's and women's perceptions of punishment appropriateness and harshness were not statistically different.

\section{Discussion}

Two aspects of these results are particularly noteworthy and merit comment. First is the fact that Black participants overall were less inclined than White participants to view ELPs both as appropriate and the described penalties as appropriately harsh. An obvious explanation for this finding is that Black Americans feel unfairly victimized by socially imposed punishments. Whether this aspect of out findings reflects an attitude towards punishment in general or more specifically, to punishment in professional sports contexts, is uncertain. Either fits the present data, though considerable evidence suggests that Black Americans are generally much less inclined than Whites to think that criminal justice processes in the United States are fair and appropriately harsh (NORC 2017).

The second notable aspect of these results is that the dominant influence on participants' perceptions of race and ELPs is an ingroup-outgroup dynamic. Consistent with recent findings by Schiller, Baumgartner, and Knoch (2014), and the neuroscientific work of Baumgartner et al. (2014), the data show that perceptions of appropriate punishments were simultaneously influenced by perceiver and perpetrator race in a manner consistent with racial ingroup-outgroup bias (see also Greenwald and Pettigrew 2014). Both Black and White participants were more lenient towards 
infractions by members of racial ingroups compared to outgroup members. However, the results are also consistent with outgroup derogation as being more influential than ingroup favouritism. This is reflected in the fact that compared to a neutral assessment (a proposed punishment that is viewed as neither too harsh nor too lenient), participants favoured relatively greater increased harshness of sanctions on the outgroup members relative to increased leniency towards ingroup members.

A possible explanation for these results is resentment or what might be called 'the schadenfreude effect' (Feather and Sherman 2002). Insofar as Blacks may resent the prevailing social status of Whites, they may be motivated to reduce the prominence of Whites relative to Blacks. Insofar as Whites resent the disproportionate representation of Black athletes in professional sports overall, they may favour changing these proportions. Whites' resentment of Blacks in political contexts has been shown to affect their attitudes towards racial tolerance (Craig and Richeson 2014a), particularly when Whites perceive a challenge to their status as the dominant group (Craig and Richeson 2014b). The effects of social identity are an additional plausible partial explanation, especially given the way athletic success is often connected to social identity. Social identity theory hypothesizes that individuals' self-esteem is strongly shaped by the groups with which they identify (Tajfel and Turner 1986).

To determine more precisely the role of these factors in ELP evaluation, further research is needed. Further research also is needed to determine the extent to which the assessment of ELPs is shaped by the sports context, as opposed to factors affecting the evaluations of punishment more generally. Another worthwhile follow-up would be to examine participant reactions to different sports. Does it matter, for example, whether participants are evaluating a player from a league dominated by Black players, such as the NBA, as compared to a majority White sport like MLB? Or does the athletes' gender matter? It might be, consistent with gender bias in other contexts, that men are disposed to be less punitive towards female athletes than are women.

\section{Limitations}

Two limitations to the present findings are worth noting. First, despite our attempts to do so, it is difficult to ensure that social desirability bias - peoples' tendency to conform to socially expected norms - did not affect the findings, perhaps in a subtle way. Second, participants may have been influenced by their knowledge of what happened in the real cases on which our scenarios were modeled. Given that recruitment procedures did not specifically target sports, however, this concern seems to be of minimal importance, and our sample was predominantly female, which likely would be associated with less familiarity with the cases.

\section{Conclusion}

One might think that sports is a competitive arena in which race is transcended and where Blacks and Whites interact on equal terms and on common ground. The present findings, however, support a less rosy view: 'far from producing a de-racializing 
effect and a space for effective anti-racist politics, contemporary hyper-commercialized sports cultures simply intensify and amplify our racial preoccupations' (Hoberman 1997, as summarized in Carrington 2010). Though ELPs raise various ethical concerns, the difficulty of insulating them from racial bias incentized by economic interests should be taken seriously. High-profile, professional sports is big business, to be sure, but also one with a significant social and even political importance. Not only do sports reflect our racial attitudes and biases, they also reinforce them. In imposing ELPs on players - even for egregious actions such as Ray Rice's - sports leagues and teams should strive to treat individuals in the most just and racially neutral way possible.

\section{Acknowledgements}

We thank Chris J.N. Lustgraaf from The University of Southern Mississippi's Department of Psychology for his programming assistance.

\section{Disclosure statement}

The authors report no conflicts of interest. The authors alone are responsible for the content and writing of this article.

\section{Notes}

1. On appeal, an arbitrator appointed by the league ruled that Commissioner Goodell overstepped his authority in suspending Rice indefinitely, since initially Rice had received only a two-game suspension from the league. However, even though eligible to play, no team has signed Rice (Maske 2014).

2. These numbers exclude the $2.6 \%$ of the population reporting two or more races (U.S. Census Bureau 2015).

3. Throughout the paper, we refer to African-Americans or Black Americans as "Blacks", following the terminology used by Plant and Devine 1998. The present study followed their method of using stereotypically Black and White names to encourage participants to perceive described characters as Black or White.

4. Murder charges against Lewis were dropped in exchange for his testimony against two friends of his related to the stabbing deaths of Jacinth Baker and Richard Lollar. After being sentenced to 12 months' probation, the NFL fined Lewis $\$ 250,000$ but did not suspend him (Freeman 2000).

5. The participant pool in this study consisted primarily of self-identified Japanese-, European- and Chinese Americans.

6. Names were derived from $A B C$ News 2006 , and common experience.

7. Nevertheless, Whites showed a similarly biased pattern of evaluation, The two post hoc comparisons are $p=.051$ and $p=.087$, which are both marginal. In other words, the same ingroup bias affects both White and Black evaluations, but it is stronger for Blacks.

\section{References}

$A B C$ News. 2006. “Top 20 'Whitest' and 'Blackest' Names.” ABC News, Septmeber 21. http:// abcnews.go.com/2020/top-20-whitest-blackest-names/story?id $=2470131$.

Agiesta, Jennifer. 2017. “CNN Poll: Americans Split on Anthem Protests." CNN.com, September 30. http://www.cnn.com/2017/09/29/politics/national-anthem-nfl-cnn-poll/index. html. 
Alexander, Michelle. 2011. The New Jim Crow: Mass Incarceration in the Age of Colorblindness. New York, NY: The New Press.

Ambrose, Robert. 2008. “The NFL Makes It Rain: Through Strict Enforcement of Its Conduct Policy, The NFL Protects Its Integrity, Wealth, and Popularity." William Mitchell Law Review 34 (3): 1070-1089.

Archer, Todd. 2017. "Cowboys RB Ezekiel Elliott Granted Stay, Eligible to Play Sunday." ESPN, November 3. http://www.espn.com/nfl/story/_/id/21273130/dallas-cowboys-rb-ezekielelliott-granted-stay-play-sunday.

Banaji, Mahzarin R., and Anthony G. Greenwald. 2016. Blindspot: Hidden Biases of Good People. New York, NY: Bantam Books.

Baumgartner, Thomas, Bastian Schiller, Jörg Rieskamp, Lorena R. R. Gianotti, and Daria Knoch. 2014. "Diminishing Parochialism in Intergroup Conflict by Disrupting the Right Temporo-Parietal Junction," Social Cognitive and Affective Neuroscience 9 (5): 653-660.

Bernstein, Ross. 2006. The Code: The Unwritten Rules of Fighting and Retaliation in the NHL. Chicago, IL: Triumph Books.

Bien, Louis. 2014. “A Complete Timeline of the Ray Rice Assault Case.” SB Nation, November 28. http://www.sbnation.com/nfl/2014/5/23/5744964/ray-rice-arrest-assault-statement-apology-ravens.

Bodenhausen, Galen V. 1990. "Stereotypes as Judgmental Heuristics: Evidence of Circadian Variations in Discrimination.” Psychological Science 1 (5): 319-322.

Bodenhausen, Galen V. 1988. "Stereotypic Biases in Social Decision Making and Memory: Testing Process Models of Stereotype Use." Journal of Personality and Social Psychology 55 (5): 726-737.

Branch, John. 2014. "N.B.A. Bars Clippers Owner Donald Sterling for Life." The New York Times, April 29. https://www.nytimes.com/2014/04/30/sports/basketball/nba-donald-sterlinglos-angeles-clippers.html?_r=2.

Brewer, Marilynn B. 1999. “The Psychology of Prejudice: Ingroup Love or Outgroup Hate?" Journal of Social Issues 55: 429-444.

Butler, Paul. 1995. "Racially Based Jury Nullification: Black Power in the Criminal Justice System.” The Yale Law Journal 105 (3): 677-725.

Carrington, Ben. 2010. Race, Sport and Politics: The Sporting Black Diaspora. Los Angeles, CA: Sage.

Chalabi, Mona. 2014. “Three Leagues, 92 Teams, and One Black Principal Owner.” FiveThirtyEight, April 28. https://fivethirtyeight.com/datalab/diversity-in-the-nba-the-nfl-and-mlb/.

Chass, Murray. 2000. "Baseball Suspends Rocker Till May for Comments." The New York Times, February 1. http://www.nytimes.com/2000/02/01/sports/baseball-baseball-suspendsrocker-till-may-for-comments.html.

Cikara, Mina, Matthew M. Botvinick, and Susan T. Fiske. 2011. "Us Versus Them: Social Identity Shapes Neural Responses to Intergroup Competition and Harm." Psychological Science 22 (3): 306-313.

Cohn, Ellen S., Donald Bucolo, Misha Pride, and Samuel R. Sommers. 2009. "Reducing White Juror Bias: The Role of Race Salience and Racial Attitudes." Journal of Applied Social Psychology 39 (8): 1953-1973.

Craig, Maureen A., and Jennifer A. Richeson. 2014a. "More Diverse Yet Less Tolerant? How the Increasingly Diverse Racial Landscape Affects White Americans' Racial Attitudes." Personality and Social Psychology Bulletin 40 (6): 1-12.

Craig, Maureen A., and Jennifer A. Richeson. 2014b. "On the Precipice of a "MajorityMinority" America: Perceived Status Threat from the Racial Demographic Shift Affects White Americans' Political Ideology." Psychological Science 25 (6): 1189-1197.

Davidson, Kavitha A. 2014. "NFL's Fumbles Become the NBA's Layups." BloombergView, November 20. https://www.bloomberg.com/view/articles/2014-11-20/nfls-fumbles-becomethe-nbas-layups.

Dickter, Cheryl L., and Bruce D. Bartholow. 2007. "Racial Ingroup and Outgroup Attention Biases Revealed by Event-Related Brain Potentials." Social Cognitive and Affective Neuroscience 2 (3): 189-198. 
ESPN. 2010. “Vick Eligible to Play in Third Week.” ESPN, September 4. http://www.espn.com/ $\mathrm{nfl} /$ news/story?id $=4442627$.

Feather, Norman T., and Rebecca Sherman. 2002. "Envy, Resentment, Schadenfreude, and Sympathy: Reactions to Deserved and Undeserved Achievement and Subsequent Failure." Personality and Social Psychology Bulletin 28 (7): 953-961.

Freeman, Mike. 2000. “Pro Football; N.F.L. Hands Ravens' Lewis a Fine of $\$ 250,000$, But Doesn't Suspend Him.” The New York Times, August 18. http://www.nytimes.com/2000/08/ 18/sports/pro-football-nfl-hands-ravens-lewis-a-fine-of-250000-but-doesn-t-suspend-him.html.

Gibbs, Lindsay. 2016. "MLB Doles Out Harshest Response Yet to Player's Domestic Violence." ThinkProgress, May 14. https://thinkprogress.org/mlb-doles-out-harshest-response-yet-toplayers-domestic-violence-93954c728dcd\#.8em2rn2c2.

Grautski, Amara. 2017. "NFL Suspends Giants kicker Josh Brown Additional 6 Games." New York Daily News, September 8. http://www.nydailynews.com/sports/football/giants/nflsuspends-giants-kicker-josh-brown-additional-6-games-article-1.3480052.

Greenwald, Anthony G., and Thomas F. Pettigrew. 2014. "With Malice Toward None and Charity for Some: Ingroup Favoritism Enables Discrimination." American Psychologist 69 (7): 669-684.

Haidt, Jonathan. 2007. “The New Synthesis in Moral Psychology.” Science 316: 998-1002.

Hiltzik, Michael. 2017. "Colin Kaepernick Certainly Seems to be the Victim of Collusion. But Can He Prove it?" Los Angeles Times, October 16. http://www.latimes.com/business/hiltzik/ la-fi-hiltzik-kaepernick-collude-20171016-story.html.

Hoberman, John. 1997. Darwin's Athletes: How Sports has Damaged Black America and Preserved the Myth of Race. Boston, MA: Mariner Books.

Hogg, Michael A., and Deborah I. Terry. 2000. "Social Identity and Self-Categorization Processes in Organizational Contexts." The Academy of Management Review 25 (1): 121-140.

Kahneman, Daniel, and Shane Frederick. 2002. "Representativeness Revisited: Attribute Substitution in Intuitive Judgement." In Heuristics and Biases: The Psychology of Intuitive Judgment, edited by Thomas Gilovich, Dale Griffin, and Daniel Kahneman, 1-30. Cambridge, UK: Cambridge University Press.

Kim, Janine Young, and Matthew J. Parlow. 2009. "Off-Court Misbehavior: Sports Leagues and Private Punishment." Journal of Criminal Law and Criminology 99 (3): 573-598.

Lapchick, Richard E. 2000. "Crime and Athletes: New Racial Stereotypes." Society 37 (3): $14-20$.

Lapchick, Richard E., and Angelica Guiao. 2015. The 2015 Racial and Gender Report Card: National Basketball Association. http://www.tidesport.org/racial-and-gender-report-cards. html.

Larrick, Richard P. 2016. "The Social Context of Decisions.” Annual Review of Organizational Psychology and Organizational Behavior 3 (1): 441-467.

Leonard, David J. 2012. After Artest: The NBA and the Assault on Blackness. Albany, NY: State University of New York Press.

Levin, Josh. 2014. "You're Fired, Roger Goodell." The Slate, September 23. http://www.slate. com/articles/sports/sports_nut/2014/09/nfl_personal_conduct_policy_the_commissioner_has_ no_business_punishing_anyone.html.

Levinson, Justin D., Huajian Cai, and Danielle Young. 2010. "Guilty by Implicit Racial Bias: The Guilty/Not Guilty Implicit Association Test.” Ohio Journal of Criminal Law 8: 187-208.

Maske, Mark. 2014. "Ray Rice Wins Appeal of NFL's Indefinite Suspension, Is Eligible to Play Immediately." The Washington Post, November 28. https://www.washingtonpost.com/news/ sports/wp/2014/11/28/ray-rice-wins-appeal-of-nfls-indefinite-suspension-is-eligible-to-playimmediately/?utm_term=.cab3e50834d0.

Mays, Vickie M., Denise Johnson, Courtney N. Coles, Denise Gellene, and Susan D. Cochran. 2013. "Using the Science of Psychology to Target Perpetrators of Racism and Race-Based Discrimination for Intervention Efforts: Preventing Another Trayvon Martin Tragedy." Journal for Social Action in Counseling \& Psychology 5 (1): 11-36. 
Mustard, David B. 2001. "Racial, Ethnic, and Gender Disparities in Sentencing: Evidence From the U.S. Federal Courts." The Journal of Law and Economics 44 (1): 285-314.

NFL. 2014. "NFL Owners Endorse New Personal Conduct Policy." NFL, December 10. http:// www.nfl.com/news/story/0ap3000000441758/article/nfl-owners-endorse-new-personal-conductpolicy.

NORC (The Associated Press-NORC Center for Public Affiars Research). 2017. "Crime and Law Enformcement in America: Racial and Ethnic Differences in Attitudes Toward the Criminal Justice System." http://www.apnorc.org/projects/Pages/HTML\%20Reports/crimeand-law-enforcement-in-america-racial-and-ethnic-differences-in-attitudes-toward-the-criminaljustice-system0402-7262.aspx\#study.

Oz, Mike. 2015. "MLB Announces New Domestic Violence Policy and Commish has Ultimate Power." Yahoo Sports, August 21. http://sports.yahoo.com/blogs/mlb-big-league-stew/mlbannounces-new-domestic-violence-policy-and-the-commish-has-ultimate-power-210356908. html.

Parlow, Matthew J. 2010. "Professional Sports League Commissioners' Authority and Collective Bargaining." Marquette Law Scholarly Commons; Faculty Publications, Paper 579. http://scholarship.law.marquette.edu/cgi/viewcontent.cgi?article $=1587 \&$ context $=$ facpub.

Pfeifer, Jeffrey E. 1990. "Reviewing the Empirical Evidence on Jury Racism: Findings of Discrimination or Discriminatory Findings?” Nebraska Law Review 69 (1): 230-250.

Pfeifer, Jeffrey E., and James R. P. Ogloff. 1991. "Ambiguity and Guilt Determinations: A Modern Racism Perspective.” Journal of Applied Social Psychology 21 (21): 1713-1725.

Piquero, Alex R., Nicole L. Piquero, Marc Gertz, Thomas Baker, Jason Batton, and J. C. Barnes. 2011. "Race, Punishment, and the Michael Vick Experience." Social Science Quarterly 92 (2): 535-551.

Plant, E. Ashby, and Patricia G. Devine. 1998. "Internal and External Motivation to Respond Without Prejudice." Journal of Personality and Social Psychology 75 (3): 811-832.

Poe-Yamagata, Eileen, and Michael Jones. 2000. And Justice for Some: Differential Treatment of Youth of Color in the Justice System. Washington, DC: Building Blocks for Youth.

Pompey, Keith. 2015. "Sixers Suspend Okafor for Two Games." The Inquirer, December 2. http://www.philly.com/philly/blogs/deep-sixer/Sixers-suspend-Okafor.html.

Schiller, Bastian, Thomas Baumgartner, and Daria Knoch. 2014. "Intergroup Bias in ThirdParty Punishment Stems from Both Ingroup Favoritism and Outgroup Discrimination." Evolution and Human Behavior 35 (3): 169-175.

Schiller, Bastian, Lorena R. R. Gianotti, Thomas Baumgartner, Kyle Nash, Thomas Koenig, and Daria Koch. 2016. "Clocking the Social Mind by Identifying Mental Processes in the IAT with Electrical Neuroimaging." Proceedings of National Academy of Sciences United States of America, 113 (10): 2786-2791.

Sirotkin, David. 2009. "Disciplining the Disciplinary Systems in Professional Sports: An Attempt to Fix the Arbitrary and Overreaching Disciplinary Powers of Sports Commissioners." Cardozo Journal of Conflict Resolution 11 (1): 289-318.

Sommers, Samuel R. 2007. "Race and the Decision Making of Jurors." Legal and Criminological Psychology 12: 171-187.

Sommers, Samuel R., and Phoebe C. Ellsworth. 2001. "White Juror Bias: An Investigation Of Prejudice Against Black Defendants In the American Courtroom.” Psychology, Public Policy \& Law 7 (1): 201-229.

Spurgin, Earl. 2012. "Hey, How Did I Become a Role Model? Privacy and the Extent of RoleModel Obligations." Journal of Applied Philosophy 29 (2): 118-132.

Stites, Adam. 2017. “Texans' Bob McNair Apologizes for Sying NFL Can't Have 'Inmates Running the Prison."' SB Nation, October 28. https://www.sbnation.com/2017/10/27/ 16559952/bob-mcnair-houston-texans-nfl-owners-meeting-protests.

Sunstein, Cass R. 2003. "Moral Heuristics." Behavioral and Brain Sciences 28 (4): 531-573.

Tajfel, Henri, and John Turner. 1986. "The Social Identity Theory of Intergroup Behavior." In Psychology of Intergroup Relations, edited by William G. Austin and Stephen Worchel, 7-24. Chicago, IL: Nelson-Hall. 
Trebon, Kimberly M. 2007. "There is No "I" in Team: The Commission of Group Sexual Assault by Collegiate and Professional Athletes." DePaul Journal of Sports Law \& Contemporary Problems 4 (1): 65-105.

Uhlmann, Eric Luis, David A. Pizarro, David Tannenbaum, and Peter H. Ditto. 2009. "The Motivated Use of Moral Principles." Judgment and Decision Making 4: 479-491.

US Census Bureau. 2015. "Quick Facts: United States." https://www.census.gov/quickfacts/ table/PST045216/00.

Van Bibber, Ryan. 2014. "Ray Rice and the Real Problem with the NFL's Personal Conduct Policy." SB Nation, July 24. http://www.sbnation.com/nfl/2014/7/24/5934035/ray-rice-suspensionnfl-personal-conduct-policy-roger-goodell.

Withers, Bethany P. 2010. "The Integrity of the Game: Professional Athletes and Domestic Violence." Journal of Sports and Entertainment Law 1 (1): 145-179. 